\title{
AVALIAÇÃO DA ATIVIDADE CICATRIZANTE DE PREPARADOS À BASE DE JUCÁ (Caesalpinia ferrea Mart.)
}

\author{
(Evaluation $n$ of healing activity preparation with basis of jucá (Cesalpinia ferrea \\ mart.)
}

\section{Emanuelle Karine Frota Batista, Hebelys Ibiapina da Trindade, Ingrid dos Santos Farias, Fernanda Maria Madeira Martins, Osmar Ferreira da Silva Filho, Maria do Carmo de Souza Batista}

${ }^{1}$ Correspondência: emanuellefrota@yahoo.com.br

RESUMO: A Cesalpinia ferrea, conhecida popularmente como jucá, possui diversas atividades farmacológicas comprovadas. Na região nordeste do Brasil está planta é frequentemente usado no tratamento de feridas cutâneas, apresentando bons resultados, o que desperta grande interesse nos estudos biotecnológicos e farmacológicos dessa espécie. $O$ objetivo desse estudo foi avaliar a atividade cicatrizante da vagem de jucá ( $C$. ferrea) isolada ou em associação com o açúcar, na cicatrização de feridas cutâneas de coelhos. Foram utilizados 40 coelhos (Oryctalagus cunicullus) adultos, divididos em cinco grupos: controle, pó das vagens in natura, pó das vagens in natura acrescido de açúcar (1:1), jucá em pomada com veículo glicerinado, e jucá acrescido de açúcar em pomada com veículo glicerinado, administrados três vezes ao dia. Após anestesia dissociativa foi realizada a confecção cirúrgica de feridas padronizadas, na dimensão de $2,5 \mathrm{~cm}^{2}$. Foram realizadas avaliações clínicas diárias, análises macroscópicas e histopatológicas das lesões nos dias três e dez após a confecção cirúrgica das feridas. Os resultados revelaram que não houve diferença significativa entre os grupos com relação ao tempo de cicatrização, porém o tratamento tópico com pomada formulada com o pó oriunda da vagem de jucá promoveu um aumento significativo da contração da área da lesão no terceiro e décimo dia.

Palavras-chave: jucá, lesão, cicatrização

ABSTRACT: The Caesalpinia ferrea, popularly known as jucá, has many proven pharmacological activities. In northeastern Brazil this plant is often used to treat skin wounds, with good results, which arouses great interest in the biotech and pharmacological studies of this kind. The aim of this study was to evaluate the healing activity of jucá pod ( $C$. ferrea) alone or in combination with sugar, healing of skin wounds in rabbits. 40 rabbits were used (Oryctalagus cunicullus) adults, divided into five groups: control, the pods powder fresh, pod powder in natura added sugar (1: 1), jucá ointment with glycerin vehicle, and jucá plus sugar glycerin ointment vehicle, administered three times a day. After anesthesia was dissociative manufacture of surgical wounds standardized in size $2,5 \mathrm{~cm}^{2}$. Daily clinical, macroscopic and histological analyzes of lesions in three ten days after the surgical preparation of the wounds were made. The results showed no significant difference between the groups regarding the healing time, but topical treatment with ointment formulated with the powder coming from jucá pod caused a significant increase in the lesion area of the contraction in the third and tenth day.

Key Words: wound healing, jucá, injury 


\section{INTRODUÇÃO}

A pele caracteriza-se como uma barreira protetora ao exterior, e quando ocorrer qualquer ruptura, essa deve ser rápida e eficientemente reparada. Ferida é toda e qualquer solução de continuidade da pele, geralmente produzida por ação traumática externa. A cicatrização é o processo pelo qual um tecido lesado é substituído por tecido conjuntivo vascularizado, para que haja restauração da função e da continuidade anatômica deste tecido (Diegelmann e Evans, 2004; Melo et al., 2009; Panobianco et al., 2012).

A cura ou reparação de feridas corresponde ao processo de cicatrização, que pode ocorrer por primeira intenção (união imediata das bordas) ou por segunda intenção (as bordas ficam separadas) havendo a necessidade de neoformação tecidual, o qual é chamado de cicatricial (Rushton, 2007). A cicatrização de feridas é um processo que envolve eventos celulares, fisiológicos e bioquímicos de modo a dar resposta à lesão do tecido. Este processo compreende três fases, são elas: inflamação, proliferação e remodelação (Pryde, 2003; Velnar et al., 2009; Demidova-Ricen et al., 2012).

A fase inflamatória inicia logo após a lesão, havendo liberação de mediadores que dão início ao processo de reparo, com migração de leucócitos e plaquetas que aderem aos vasos sanguíneos danificados, iniciando uma reação hemostática. Em seguida iniciase a fase proliferativa ou granulação, em que ocorre a epitelização (migração de células epiteliais sobre a área lesada), neovascularização, produção de colágeno pelos fibroblastos e contração da ferida. Por último, sucede a fase remodelação, que dura meses e tem como meta a melhoria nos componentes das fibras colágenas e a reabsorção de água para aumentar a força da cicatriz e diminuir sua espessura (Pryde, 2003;
Kede, 2009; Demidova-Rice et al., 2012; Flanagen, 2013).

Embora não se possa acelerar o processo de cicatrização, existem vários fatores, locais e sistêmicos, que afetam adversamente a cicatrização das feridas como idade, estado fisiológico, condições nutricionais, temperatura e principalmente pela instituição ou não de medidas terapêuticas adequadas (Mandelbaum et al., 2003; Neto, 2003; Rushton, 2007; Borges, 2008).

A utilização de plantas medicinais e produtos naturais é uma prática comum no país e representa uma grande possibilidade de descoberta de substâncias que possam influenciar positivamente o processo cicatricial, sobretudo reduzir a fase inflamatória, que é a que ocasiona mais desconforto ao paciente (Veiga Júnior et al., 2005). No processo de cicatrização de feridas, sua utilização não se difere, elas são mencionadas desde a pré-história, quando eram utilizados plantas e extratos vegetais, na forma de cataplasmas, com o intuito de estancar hemorragias e favorecer a cicatrização, sendo muitas dessas plantas ingeridas, para atuação em via sistêmica (Silva e Mocelin, 2007).

O emprego de plantas medicinais na recuperação de feridas tem evoluído ao longo dos tempos desde as formas mais simples de tratamento local (provavelmente utilizada pelo homem das cavernas) até as formas tecnologicamente sofisticadas da fabricação industrial utilizadas pelo homem moderno (Lorenzi e Matos, 2002). Como as perdas de pele nos animais são muito frequentes e oriundas de diferentes causas, é importante diversificar as opções de tratamento a fim de se obter condições específicas para cada situação (Oliveira et al., 2010).

A espécie Caesalpinia ferrea Mart. pertence à família Fabaceae. É uma espécie nativa do Brasil, 
principalmente na região Amazônica e caatinga nordestina, conhecida popularmente como jucá, pau-ferro, ibirá-obi, muirá-obi, muiré-itá (Souza, 2007). Há pesquisas comprovando a utilização desta planta como antibacteriano e antifúngico (Lima et al., 1997; Ximenes, 2004), como a antiulcerativa (Bacchi e Sertié, 1994; Bacchi et al., 1995), analgésica e antiinflamatória (Carvalho et al., 1996) e antibacteriana (Sampaio et al., 2009). Os frutos são utilizados como antidiarréicos, anticatarrais e cicatrizantes e as raízes são antipiréticas (Maia, 2004). Seu uso também é relatado para afecções bronco-pulmonares, diabetes, reumatismo, câncer, distúrbios gastrintestinais, diarréia, inflamação e dor (Nakamura, 2002; Frasson et al., 2003; Gomes, 2003).

Avaliando a ação cicatrizante de Caesalpinia férrea, Oliveira et al. (2010) observaram que as feridas tratadas com - pó da casca desta planta apresentaram processo de cicatrização mais acelerado que o grupo controle, tratados com vaselina, pela análise histológica. Também em modelo experimental, foi testada a ação antiinflamatória do extrato etanólico do fruto de $C$. ferrea, com inibição do edema na orelha induzido com xileno, com resultado de $66,6 \%$ comparado a $16,4 \%$ do grupo controle (Lima et al., 2011). Na região nordeste do Brasil o pó da casca de $C$. ferrea,é frequentemente usado no tratamento de feridas cutâneas, apresentando bons resultados, o que desperta grande interesse nos estudos biotecnológicos e farmacológicos dessa espécie (Ximenes, 2004).

A análise química das folhas e caule de C. ferrea, demonstrou a presença de flavonóides, saponinas, taninos, esteróis e compostos fenólicos (Gonzalez et al., 2004; Oliveira et al., 2010).
Em relação ao uso terapêutico do açúcar, suas primeiras indicações clínicas foram descritas na antiguidade com o uso do mel ou do melado (Prata et al., 1988). As ações obtidas com o emprego do açúcar em feridas são: oferta de nutrição às células lesadas, diminuição do odor exalado, drenagem de exsudação, redução do edema inflamatório, diminuição do pH, dilatação dos pequenos vasos sanguíneos, formação de uma camada protetora de proteína, liberação de calor ao dissolverse, atração de macrófagos reduzindo a necessidade de debridamento cirúrgico e estimulação dos tecidos de granulação e epitelial (Mathews e Binnington, 2002). Também possui efeito benéfico no tratamento de feridas infectadas devido ação bactericida ou bacteriostático, além das propriedades supracitadas (Petrucci et al., 2009).

Considerando que o jucá e o açúcar são popularmente empregados na cura de ferimentos, este estudo foi conduzido com o objetivo de avaliar macroscópica e microscopicamente o efeito do pó e pomada formulada a partir da vagem da planta, isoladamente e em associação com 0 açúcar, na cicatrização de feridas de coelhos, por segunda intenção.

\section{MATERIAL E MÉTODOS}

No Centro de Ciências Agrárias (CCA) da Universidade Federal do Piauí (UFPI), a pesquisa foi desenvolvida utilizando-se coelhos como modelo animal para a abordagem sobre a cicatrização.

\section{Animais}

Foram utilizados um total de 40 coelhos (Oryctalagus cunicullus) machos adultos, sem padrão racial definido, com peso variando entre três a cinco quilogramas, distribuídos aleatoriamente em cinco grupos de oito 
animais, mantidos em condições uniformes de manejo, recebendo ração balanceada e água ad libidum, além de uma suplementação com capim elefante napier e alface. $\mathrm{O}$ experimento recebeu parecer favorável do Comitê de Ética em Experimentos com Animais da UFPI, número 095/2010 (CEEA-UFPI).

\section{Coleta da vagem de Jucá}

As vagens de jucá foram colhidas no Campus da UFPI. A espécie foi identificada como Caesalpinia ferrea Mart. A exsicata recebeu o número TEPB: 3447 e foi depositada no herbário Graziela Barroso -UFPI.

Para a obtenção do pó de jucá, as vagens da planta foram colhidas, levadas ao Laboratório de Ciências Fisiológicas do Departamento de Morfofisiologia Veterinária do CCAUFPI, lavadas em água corrente e imersas em solução de hipoclorito de sódio a $2 \%$ por 10 minutos e posteriormente dessecadas ao sol durante dois dias. A seguir foram fragmentadas e trituradas em moinho elétrico, passadas em peneira de malha fina para obtenção do pó, utilizado como matéria prima para a confecção das pomadas.

\section{Preparo das formulações}

As formulações, descritas abaixo, foram preparadas em ambiente laboratorial, utilizando-se glicerina líquida como veículo para produção das pomadas.

Pó 1: sólido pulverizado oriundo das vagens de jucá in natura.

Pó 2: sólido pulverizado oriundo das vagens de jucá in natura acrescido açúcar granulado (2:1).

Pomada 1: vagem de jucá em pó (24g), glicerina qsp $100 \mathrm{~g}$.

Pomada 2: vagem de jucá em pó (16 g), açúcar granulado (8g), glicerina em qsp 100g.
Cada formulação foi

acondicionada em recipiente plástico esterilizado contendo cânula para facilitar a administração.

\section{Confecção das feridas experimentais}

Após a montagem do delineamento experimental, realizou-se a confecção das feridas pelo método cirúrgico, mediante prévia anestesia dissociativa utilizando-se cetamina associada à xilazina $(30 \mathrm{mg} / \mathrm{kg}$ com $4 \mathrm{mg} / \mathrm{kg}$, respectivamente), por via intramuscular. Após a anestesia dos animais selecionou-se a região dorsolateral direita da linha media dorsal realizando-se tricotomia. As feridas foram demarcadas usando-se um molde de esparadrapo com $2,5 \mathrm{~cm}^{2}$ e produzidas cirurgicamente, retirando-se a pele e tecido subcutâneo.

\section{Tratamento das feridas}

Decorridas 24 horas após a cirurgia, iniciou-se o tratamento tópico das feridas, conforme o delineamento detalhado no Quadro 1.

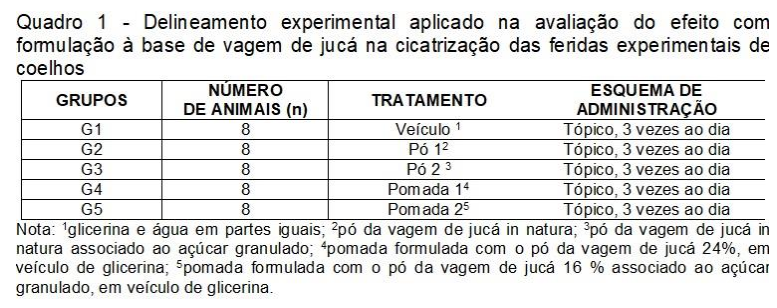

\section{Avaliação macroscópica}

A avaliação macroscópica do processo cicatricial foi feita pela observação diária das feridas, verificando-se a ocorrência de hiperemia, exudação e aspecto da crosta (Martins 2010; Batista et al., 2014), considerando a ferida cicatrizada quando ocorreu o fechamento total da pele.

Para avaliar a progressão da cicatrização e o efeito do tratamento 
sobre a fase mais crítica, que é a inflamatória, procedeu-se a mensuração da área das feridas com o auxílio de um paquímetro nos dias 0 (imediatamente após a cirurgia), 3, 10 e 17 de pósoperatório e para calculá-la utilizou-se a equação descrita por Prata et al. (1988): $A=\pi . R . r$, onde "A" significa a área, "R" o raio maior e "r" o raio menor da ferida. A contração da ferida foi avaliada por meio da seguinte fórmula: (área inicial área do dia da medida) $\div$ pela área inicial $\times 100=$ percentual de contração do dia (Agren et al., 1997). Todas as medidas foram aferidas pelo mesmo operador e o percentual de contração da ferida foi expresso como grau de reparação tissular.

\section{Avaliação histopatológica}

Nos dias 3 e 10 após a cirurgia foram retirados fragmentos de dois animais de cada grupo para avaliação histopatológica das lesões, sendo que os animais utilizados na coleta de material, para estudo microscópico não foram contados na análise do tempo final de cicatrização, uma vez que suas lesões foram ampliadas. Os fragmentos retirados foram fixados em formol tamponado a $10 \%(\mathrm{pH} 7)$ por período de 24 horas, desidratados em álcool, diafanizados em xilol, incluídos em parafina, cortados em $5 \mu \mathrm{m}$. Foram preparadas duas lâminas para cada animal, as quais foram coradas pelas técnicas de Hematoxilina-Eosina e Tricrômico de Masson. O campo histológico de cada lâmina foi avaliado através dos critérios: inflamação aguda, inflamação crônica inespecífica, proliferação fibroblástica, colagenização e reepitelização da ferida. A quantificação de cada variável observada seguiu o esquema: ausente $=0$, discreta $=1$, moderada $=2 \mathrm{e}$ acentuada $=3$.

\section{Análise estatística}

Utilizou-se a análise de variância (Anova) e o teste de Tukey ao nível de $5 \%$ de probabilidade, para avaliar 0 tempo final de reparação das lesões (expresso em dias) e os percentuais de contração das feridas (expressos em média \pm desvio padrão). A análise estatística dos parâmetros histológicos foi realizada pelo método não paramétrico de Kruskal-Wallis com significância de 5\%.

\section{RESULTADOS E DISCUSSÃO}

O estudo macroscópico do efeito das formulações com a vagem de jucá (Caesalpinia férrea), com e sem a adição de açúcar, nos diferentes esquemas de administração, na terapêutica tópica de feridas cutâneas, consistiu-se na observação clínica diária das lesões e mensuração da área das feridas.

$\mathrm{Na}$ avaliação clínica diária das feridas foram observados edema, hiperemia e formação de crostas em todos os grupos, no terceiro dia após a cirurgia, entretanto, os sinais de exsudação foram menos evidentes nos grupos tratados com as formulações em pó. A utilização de jucá (C. ferrea) no tratamento de feridas cutâneas mostrase benéfico, principalmente nos primeiros dias de pós-operatório, devido à formação de uma crosta escura aderindo toda lesão, favorecendo a reparação tecidual.

Essa formação de crosta possivelmente pode ser explicada pela riqueza de taninos na sua composição, que promove proteção física impedindo a penetração e multiplicação de microrganismo do meio externo no leito da ferida, assim como a perda de água e calor do tecido de granulação (Monteiro, 2003; Gonzalez et al., 2004). Segundo Andrade (2006), a presença de crosta em uma ferida não é pré- 
requisito para a cicatrização podendo apresentar vantagens e desvantagens para a evolução do processo cicatricial, funcionando como barreira física, protegendo de contaminação e servindo de bandagem natural, mas podendo apresentar um aspecto seco e retardar a contração da pele durante o processo de cicatrização.

A análise geral do tempo médio de cicatrização mostrou que os preparados com a vagem de jucá, com e sem a adição de açúcar não influenciaram significativamente o tempo final de cicatrização de feridas limpas de coelhos, por segunda intenção (Tabela 1).

Tabela 1 - Tempo médio de cicatrização de feridas experimentais de coelhos, tratadas topicamente com formulações à base da vagem de jucá, isoladamente e em \begin{tabular}{c|cc} 
associação a açúcar, três vezes ao dia & \\
\hline GRUPOS & TRATAMENTOS & TEMPO MÉDIO DE CICATRIZAÇÃO (DIAS)
\end{tabular}

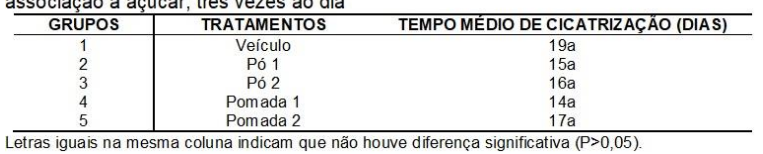

Analisando-se a evolução do processo de cicatrização através do percentual de inibição da área da lesão, calculado a partir da mensuração da área das feridas no terceiro, décimo e décimo sétimo dia após a cirurgia, verificou-se que ocorreu redução gradual em todos os grupos, porém nos grupos tratados com as pomadas a redução foi mais acentuada, sobretudo no grupo 4, tratado com a pomada 1 (Tabela 2), 0 qual diferiu significativamente do grupo controle. $\mathrm{Em}$ todos os grupos tratados com as formulações contendo jucá, com e sem açúcar, ocorreu aumento numérico da contração da área cruenta, se comparado ao controle (Tabela 2).

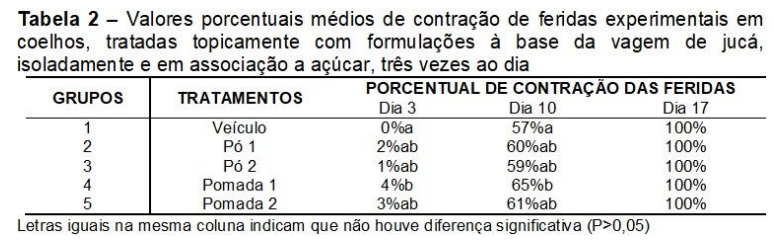

Com relação ao efeito do açúcar nas formulações com jucá, observou-se que este não influenciou significativamente o processo cicatricial, pois não houve diferenças significativas entre as formulações (Tabelas 1 e 2).

Quanto às análises histológicas, não foram observadas diferenças significativas entre grupos, ao longo do período experimental. Esses dados corroboram com Fernandes (2013), que não observou diferenças histológicas nas feridas tratadas com jucá quando comparadas ao grupo controle. Entretanto, Oliveira et al. (2010) observaram que as feridas do grupo controle, tratadas com vaselina, necessitavam de maior tempo para cicatrização em relação as feridas tratadas com jucá aos 21 dias de tratamento.

Observou-se que a proliferação vascular foi mais uniforme no grupo tratado com a pomada 1 (formulada com o pó da vagem em veículo de glicerina) no terceiro dia e perdurou até o décimo dia. Os vasos sanguíneos oriundos da angiogênese, que tem como consequência a formação do tecido de granulação. Esse processo de neovascularização ocorre para restabelecer o fluxo sanguíneo e consequentemente a oxigenação no local da ferida, sendo esses novos vasos um dos primeiros constituintes do tecido de granulação (Berry e Sullins, 2003; Neto, 2003; Werner e Grose, 2003; Kumar et al., 2005).

A proliferação fibroblástica também foi mais uniforme no grupo tratado com a pomada 1 , com achados variando de moderado a acentuado, no décimo dia de tratamento. No grupo controle, a proliferação fibroblástica mostrou-se discreta em todos os períodos de observação. A reepitelização foi uniforme nos grupos tratados com as pomadas 1 e 2. As fibras colágenas estavam aumentadas em todos os grupos, no décimo primeiro dia de avaliação, ocorrendo de forma 
mais organizada nos tratamentos com as pomadas 1 e 2 .

Resultados semelhantes foram observados por Soares et al. (2013), que trataram topicamente ratos winstar com pomadas a base de jucá a $10 \%$ e observaram grande quantidade de neovasos, presença de discreta crosta fibrino leucocitária e de infiltrado leucocitário. Oliveira et al. (2010) avaliaram a ação cicatrizante de pomada a base de jucá em caprinos e constataram completo processo de reepitelização, com tecido conjuntivo apresentando grande quantidade de fibroblastos ativos, fibras colágenas melhor organizadas e pequena quantidade de vasos sanguíneos.

A proliferação endotelial e fibroblástica ocorrem com a formação do tecido de granulação, que depende das linfocinas, que vão estimular células endoteliais, fibroblastos e macrófagos, entre outras substâncias (Neto, 2003; Sarandy, 2007).

O tratamento tópico com preparações à base do pó da vagem de jucá, sobretudo com pomada onde o pó foi incorporado em veículo glicerinado, com e sem adição de açúcar, desencadeia um processo cicatricial esteticamente mais organizado, menos hiperêmico e exsudativo, indicando que intervém beneficamente no processo cicatricial, minimizando eventos da fase inflamatório.

\section{CONCLUSÃO}

Este estudo permitiu concluir que a aplicação tópica da vagem de jucá, três vezes ao dia, nas formulações em pó e pomada, com e sem açúcar granulado, não reduz significativamente o tempo de cicatrização, por segunda intenção, em feridas limpas de coelho. Porém a pomada formulada com o pó da vagem a $24 \%$ produz aumento significativo do percentual de contração da área cruenta, fato constatado nas observações realizadas no terceiro dia e décimo dia após a confecção das feridas. Este fato reveste-se de importância, visto que, atualmente, busca-se estratégias terapêuticas que minimizem a fase inicial de cicatrização, que é a fase inflamatória do processo, aquela que causa mais desconforto ao paciente.

\section{REFERÊNCIAS}

ANDRADE, L.S.S. Avaliação terapêutica das pomadas do polissacarídeo Anacardium Occidentale L. e do extrato em pó da Jacaratia corumbensis 0 . kuntze em feridas cutâneas produzidas experimentalmente em caprinos (Capra Hircus L.) Aspectos clínicos, bacteriológicos e histopatológicos. 2006. 85p. Tese (Doutorado em Ciência Veterinária - Departamento de Medicina Veterinária), Universidade Federal rural de Pernambuco.

BACCHI, E.M.; SERTIÉ, J.A.A. Antiulcer action of Styrax comporum and Caesalpinia ferrea in rats. Planta Médica, v. 60, p.118-120, 1994.

BACCHI, E.M. et al. Antiulcer action and toxicity of Styrax comporum and Caesalpinia ferrea. Planta Médica, v. 61, n. 3, p.204-207, 1995.

BATISTA, E. K, F. et al. Avaliação do efeito de formulações com o látex da Euphorbia tirucalli na terapêutica tópica de feridas cutâneas: aspectos clínicos e histopatológicos. Medicina Veterinária, Recife, v.8, n.2, p.1-11, 2014.

BERRY, D. B.; SULLINS, K. E. Effects of topical application of antimicrobials and bandaging on healing and granulation tissue formation in wounds of the distal aspect of the limbs in horses. American Journal of Veterinary Research, v.64, p.88-92, 2003.

BORGES, E. L. Evolução da cicatrização. In: BORGES, E. L.; SAAR, 
S. R. C.; MAGALHÃES, M. B. B.; GOMES, F. S. L.; LIMA, V. L. A. N. Feridas: como tratar. 2 ed. Belo Horizonte: Coopmed, 2008. p. 31-43.

CARVALHO, J. C. T. et al. Preliminary studies of analgesic and antiinflammatory properties of Caesalpinia ferrea crude extract. Journal of Ethnopharmacology, v. 53, p.175-178, 1996.

DEMIDOVA-RICE, T. N.; HAMBLIN, M. R.; HERMAN, I. M. Acute and impaired wound healing: Pathophysiology and current methods for drug delivery, Part1: Normal and chronic wounds: Biology, causes, and Approaches to care. Adv Skin Wound Care, vol. 25, n. 7, p. 304314, 2012.

DIEGELMANN, R. F.; EVANS, M. C. Wound healing: an Overview of Acute, Fibrotic and Detayed Healing. Fronties Bioscience, v.9, p.283-289, 2004.

FERNANDES, C. P. M. Avaliação da ação cicatricial e repelente de Carapa guianensis e Caesalpinia ferrea Mart. 2013, 65 f. Dissertação (Mestrado em Ciências). Universidade Federal de Pelotas. 2013.

FLANAGEN, M. Wound healing and skin integrity: principles and practice. Hoboken: Wiley-Blackwell; 2013.

FRASSON, A. P. Z. et al. Caracterização físico-química e biológica do caule de Caesalpinia ferrea Mart. Revista Brasileira de Farmacognosia, v.13, n.1, p.35-39, 2003.

GOMES, M. As plantas da saúde: guia de tratamentos naturais. 3.ed. São Paulo: Paulinas, 2003. 351p.

GONZALEZ, F.G. et al. Atividade Antioxidante e perfil fitoquímico de Caesalpinia ferrea MArt. In: SEMANA DA FARMACÊUTICA DE CIÊNCIA E TECNOLOGIA, 9., 2004, São Paulo. Anais... São Paulo: Revista Brasileira de Ciências Farmacêuticas, 2004. v.40. p.79.

KEDE, M. P. V. Dermatologia estética. São Paulo: Atheneu; 2009.

KUMAR, V.; ABBAS, A. K.; FAUSTO, N. Inflamação aguda e crônica. In: KUMAR, V. et al. (eds.) Robbins e Cotran. Patologia - bases patológicas das doenças. 7ed. Rio de Janeiro: Elsevier, p. 49-90, 1592 p. 2005.

LIMA, E. C. Atividade antifúngica de extratos obtidos de espécies de leguminoseae contra dermatófitos. Revista Brasileira de Ciências da Saúde, v.1, n.13, p.53-56, 1997.

LIMA, S. M. A. et al. Potencial antiinflamatório e analgésico da Caesalpinia ferrea. Revista Brasileira de Farmacognosia, v. 22, n.1, p.169175, 2011.

LORENZI, H. F.; MATOS, F. J. A. Plantas medicinais do Brasil, nativas e exóticas. Nova Odessa - SP: Instituto Plantarum, 2002. 512p.

MAIA, G. N. Caatinga: árvores e arbustos e suas utilidades. São Paulo: D\&Z Computação Gráfica, Leitura \& Arte, 413 p. 2004.

MANDELBAUM, $\mathrm{S}$. $\mathrm{H}$. et al. Cicatrização: conceitos atuais e recursos auxiliares - Parte I. Anais Brasileiros de Dermatologia, v. 78, n. 4, p.393-410, 2003.

MARTINS, J. M. Uso da babosa (Aloe vera) na reparação de feridas abertas provocadas cirurgicamente em cães. 2010. 55f. Monografia (Curso de Medicina Veterinária). Universidade Federal de Campina Grande, Paraíba.

MATHEWS, K. A.; BINNINGTON, A. G. Wound management with sugar. Compendium on Continuing Education for the Practicing Veterinarian, v.24, n.1, p.41-50, 2002.

MELO, U.P. et al. Fisiopatologia da cicatrização das feridas nos equinos. 
Revista do Conselho Federal de Medicina Veterinária, v.15, n.48 p.3242, 2009.

MONTEIRO, V.L.C. Reparação tecidual de feridas cutâneas de caprinos tratadas com polissacarídeo de cajueiro Anacardium occidentale L.: estudo clinico, bacteriológico e histopatológico. $2003 . \quad 50 p$. Dissertação (Mestrado em Ciência Veterinária) Departamento de Medicina Veterinária, Universidade Federal de Rural de Pernambuco, Recife. 2003.

NAKAMURA, E. S. Cancer chemopreventive effects of Caesalpinia ferrea and related compounds. Cancer Letters, v. 177, n. 2, p. 119-124, 2002.

NETO, J. C. L. Considerações sobre a cicatrização e o tratamento de feridas cutâneas em equinos, 2003. Online. Disponível na internet http://br.merial.com/pdf/arquivo8.pdf

OLIVEIRA, A. F. et al. Avaliação da atividade cicatrizante do jucá (Caesalpinia ferrea Mart. ex Tul. var. ferrea) em lesões cutâneas de caprinos. Revista Brasileira de Plantas Medicinais, vol.12, n.3, p.302-310, 2010.

PANOBIANCO, M. S. et al. Comparação da cicatrização pós-mastectomia entre mulheres portadoras e não-portadoras de diabetes mellitus. Revista da Rede de Enfermagem do Nordeste, vol. 11, p.15-22, 2012.

PETRUCCI, M. P. et al. Utilização do açúcar como terapêutica alternativa no processo cicatricial em coelho doméstico (Oryctolagus cuniculus): relato de caso. Jornal Brasileiro de Ciência Animal, vol. 2, n. 3, 2009.

PRATA, M. B. et al. Uso tópico do açúcar em ferida cutânea: estudo experimental em rato. Acta Cirúrgica Brasileira, vol. 3, p. 43-8, 1988.

PRYDE, J. A. Inflammation and Tissue In: M. H. Cameron. Physical Agents in
Rehabilitation: From Research to Practice. $2^{\mathrm{a}}$ ed., St Louis Missouri: Saunders. 2003. pp. 13-34.

RUSHTON, I. Understanding the role of proteases and $\mathrm{pH}$ wound healing. Nursing Standart, v. 21, n. 32, p. 6874, 2007.

SAMPAIO, F. C. et al. In vitro antimicrobial activity of Caesalpinia ferrea Martius fruits against oral pathogens. Journal of Ethnopharmacology, v. 124, p.289294, 2009.

SARANDY, M. M. Avaliação do efeito cicatrizante do extrato de repolho (Brassica oleracea var. capitata) em ratos wistar. 2007. Dissertação (Mestrado em Biologia Celular e Estrutural), Universidade Federal de Viçosa, Viçosa, Minas Gerais. 2007.

SILVA, D. M.; MOCELIN, K. R. O cuidado de enfermagem ao cliente portador de feridas sob a ótica do cuidado transcultural. Nursing, v. 9, n. 105, p. 8188, 2007.

SOARES, J. A. et al. Avaliação da atividade cicatrizante da Caesalpinia férrea ex. TUL. var ferrea e da Aloe vera (L.) Burm. f. em lesões cutâneas totais em ratos. Perspectivas online: Biologia \& Saúde, vol. 11, n. 3, p. 3342, 2013.

SOUZA, L. A. G. Leguminosas da Amanzônia: Jucá - Caesalpinia férrea Mart. Manaus: INPA, 2007.

VEIGA JÚNIOR, V. F. et al. Plantas medicinais: cura segura? Química Nova, v. 28, n. 3, p.19-528, 2005.

VELNAR, T.; BAILEY, T.; SMRKOJI, V. The wound healing process: an overview of the cellular and molecular mechanisms. The Journal of International Medical Research, vol. 37, n. 5, p. 1528-1542, 2009.

WERNER, S.; GROSE, R. Regulation of wound healing by growth factors and 
cytokines. Physiological Reviews. Vol. 83, n. 3, p. 835-70, 2003.

XIMENES, N.C.A. Purificação e Caracterização da Lectina da Vagem da Caesalpinia ferrea (Cf e PL): aplicação biológica. 2004. 53p. Dissertação (Mestrado em Bioquímica Departamento de Bioquímica) - Centro de Ciências Biológicas, Universidade Federal do Pernambuco, Recife. 2004. 